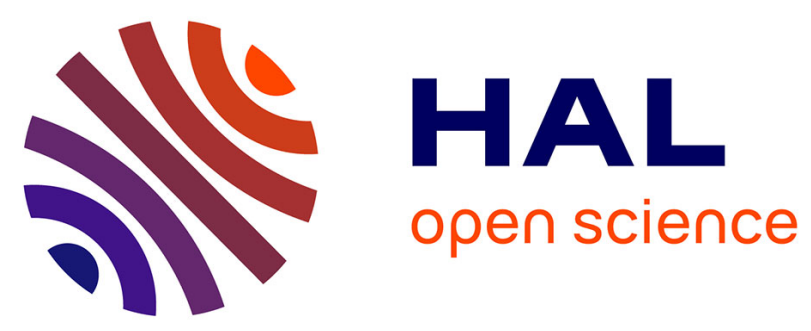

\title{
Beyond the compositional threshold of nanoparticle-based materials
}

\author{
David Portehault, Simon Delacroix, Guillaume Gouget, Remi Grosjean, \\ Tsou-Hsi-Camille Chan-Chang
}

\section{- To cite this version:}

David Portehault, Simon Delacroix, Guillaume Gouget, Remi Grosjean, Tsou-Hsi-Camille ChanChang. Beyond the compositional threshold of nanoparticle-based materials. Accounts of Chemical Research, 2018, 51 (4), pp.930-939. 10.1021/acs.accounts.7b00429 . hal-01883831

\section{HAL Id: hal-01883831 \\ https://hal.sorbonne-universite.fr/hal-01883831}

Submitted on 28 Sep 2018

HAL is a multi-disciplinary open access archive for the deposit and dissemination of scientific research documents, whether they are published or not. The documents may come from teaching and research institutions in France or abroad, or from public or private research centers.
L'archive ouverte pluridisciplinaire HAL, est destinée au dépôt et à la diffusion de documents scientifiques de niveau recherche, publiés ou non, émanant des établissements d'enseignement et de recherche français ou étrangers, des laboratoires publics ou privés. 


\section{Beyond the compositional threshold of nanoparticle-based materials}

David Portehault, ${ }^{1, *}$ Simon Delacroix, ${ }^{1,2}$ Guillaume Gouget, ${ }^{1, \$}$ Rémi Grosjean, ${ }^{1,2, \#}$ Tsou-HsiCamille Chan-Chang ${ }^{1}$

${ }^{1}$ Sorbonne Université, CNRS, Collège de France, Laboratoire Chimie de la Matière Condensée de Paris, LCMCP, 4 Place Jussieu, F-75005 Paris, France.

${ }^{2}$ Sorbonne Université, CNRS, MNHN, IRD, Institut de Minéralogie, de Physique des Matériaux et de Cosmochimie, IMPMC, 4 Place Jussieu, F-75005 Paris, France.

CORRESPONDING AUTHOR: david.portehault@upmc.fr

\section{CURRENT ADDRESSES:}

\$ G.G.: Department of Chemistry, University of Pennsylvania, Philadelphia, Pennsylvania 19104, United States

\# R.G.: Laboratoire de Synthèse et Fonctionnalisation des Céramiques, UMR3080 CNRS/SaintGobain CREE, 84300 Cavaillon, France 


\section{CONSPECTUS}

The design of inorganic nanoparticles relies strongly on the knowledge from solid state chemistry not only for characterization techniques, but also and primarily for choosing the systems that will yield the desired properties. The range of inorganic solids reported and studied as nanoparticles is however strikingly narrow when compared to the solid state chemistry portfolio of bulk materials. Efforts to enlarge the collection of inorganic particles are becoming increasingly important for three reasons. First, they can yield materials more performing than current ones for a range of fields including biomedicine, optics, catalysis and energy. Second, looking outside the box of common compositions is a way to target original properties or to discover genuinely new behaviors. The third reason lies in the path followed to reach these novel nano-objects: exploration and set-up of new synthetic approaches.

Indeed, willingness to access original nanoparticles faces a synthetic challenge: how to reach nanoparticles of solids that originally belong to the realm of solid state chemistry and its typical protocols at high temperature? To answer this question, alternative reaction pathways must be sought, which may in turn provide tracks for new, untargeted materials. The corresponding strategies require limiting particle growth by confinement at high temperatures or by decreasing the synthesis temperature. Both approaches, especially the latter, provide a nice playground to discover metastable solids never reported before.

The aim of this account is to raise attention to the topic of the design of new inorganic nanoparticles. To do so, we take the perspective of our own work in the field, by first describing synthetic challenges and how they are addressed by current protocols. We then use our achievements to highlight the possibilities offered by new nanomaterials and to introduce 
synthetic approaches that are not in the focus of recent literature but hold, in our opinion, great promises. We will span methods of low temperature "chimie douce" aqueous synthesis coupled to microwave heating, sol-gel chemistry and processing coupled to solid state reactions, and then molten salt synthesis. These protocols pave the way to metastable low valence oxyhydroxides, vanadates, perovskite oxides, boron carbon nitrides and metal borides, all obtained at the nanoscale with structural and morphological features differing from "usual" nanomaterials. These nano-objects show original properties, from sensing, thermoelectricity, charge and spin transports, photoluminescence and catalysis, which require advanced characterization of surface states. We then identify future trends of synthetic methodologies that will merit further attention in this burgeoning field, by emphasizing the importance of unveiling reaction mechanisms and coupling experiments with modelling.

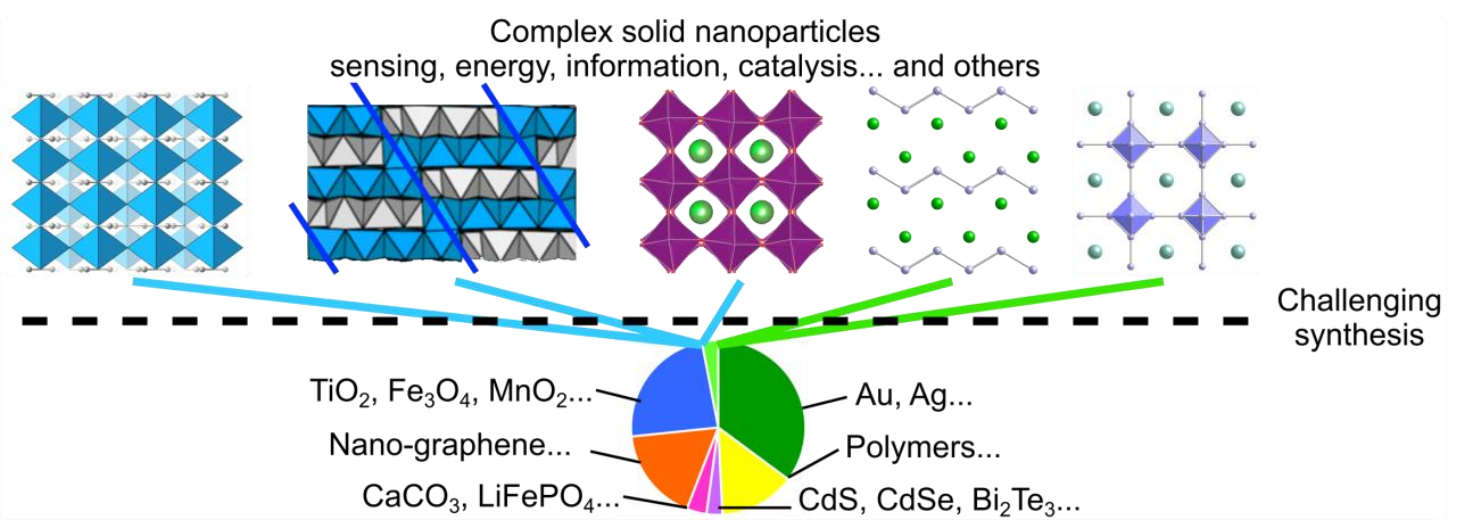




\section{Introduction}

Design and study of nanoparticle ${ }^{1}$-based materials is an interdisciplinary field implying solidstate chemistry and physics, molecular and solution chemistry when gas-phase or liquid-phase syntheses are involved, and all areas related to applications - biology, medicine, optics, catalysis, electrochemistry and energy. This entanglement is source of richness, of excitation and inspiration for scientists.

Some gaps however persist between chemistry of the nanoscale and solid-state chemistry that addresses primarily bulk materials. The synthetic tools may differ by the temperature $(T)$ ranges involved (usually $\sim 20-300{ }^{\circ} \mathrm{C}$ for nanoparticle design, $\sim 300-2000{ }^{\circ} \mathrm{C}$ for solid-state reactions). The characterization techniques may also diverge because of crystalline domains below $10 \mathrm{~nm}$ (resulting in poorly resolved X-ray diffraction patterns). But the largest discrepancy, although not frequently quoted, lies in the materials of interest: the range of solids developed as nanoparticles is still narrow compared to the various phases reported from solidstate chemistry. Evidence for this statement is provided by a literature search in chemistry, materials science, nanoscience and nanotechnology (Figure 1). Oxides, metals and their alloys are the most studied, with multiple applications at stake. Polymer-based and carbonaceous nanoparticles are also largely investigated. Chalcogenide research is supported by optoelectronics and biomedicine, ${ }^{2}$ while polyanionics (e.g. carbonates) are primary biominerals. The $3 \%$ remaining articles deal with all other materials. Refinement of this list with exact compositions would show that most oxide nanoparticles are "common" binary transition metal oxides with high metal oxidation state. Hence, the richness of phase space expressed in the solid-state chemistry portfolio of bulk materials does not transpose to the chemical composition of nanoparticles. 


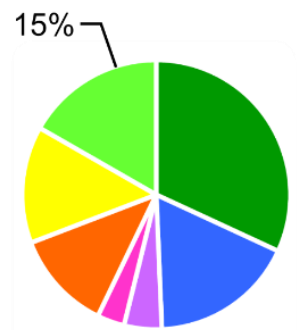

2005

13700 articles

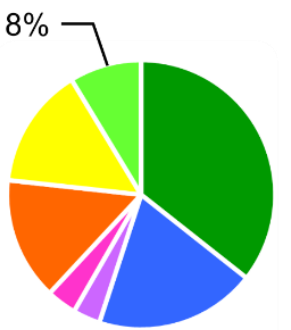

2010

62700 articles

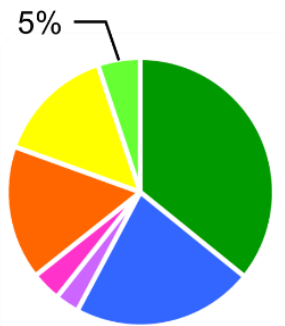

2014 147400 articles

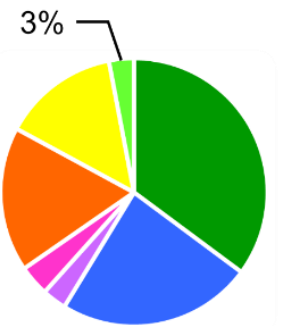

2017

235700 articles gold/silver/alloys

oxides

chalcogenides

polyanionics

carbon

polymers

others

Figure 1. Nanoparticles families investigated from 2000 until 2005, 2010, 2014 and $2017 .{ }^{3}$

We will point out some reasons for this discrepancy, but let us first wonder why it is important to search outside reported compositions. Firstly, many bulk solids exhibit (technologically important) properties without equivalent among materials commonly met as nanoparticles. For instance, cubic boron nitride is one of the hardest materials after diamond, with higher thermal and chemical stability. When $c$-BN monoliths are formed under pressure by sintering $c$-BN nanocrystals, hardness increases as dislocations cannot propagate across grain boundaries. ${ }^{4}$ Metal phosphides are also intensively searched as electrocatalysts for the Hydrogen Evolution Reaction (HER). ${ }^{5}$ Nanoparticles increase the surface-to-volume ratio and the massnormalized catalytic activity. ${ }^{5}$ These two examples highlight the importance of investigating novel families of materials at the nanoscale, which is then motivated by the expected properties. A second answer is illustrated by John Corbett's words: "It is always difficult to predict the unimaginable". 6 Searching pathways to nanoparticles with new compositions is a mean to discover surprising properties, which will supply basic research and applied fields with new concepts. It can also unveil novel synthetic strategies that could apply to other materials. As computational advances have not yet gone far enough to predict phase behaviors and properties of nano-objects, ${ }^{7-9}$ synthetic exploration is a great way to discover novel properties and materials. 
This Account is not an exhaustive review of the efforts made to extend the phase space of nanoparticles. Therefore, many reports worth mentioning may not be referenced. Our purpose is rather to raise attention to the topic, by highlighting the possibilities offered by such new nanomaterials and synthetic approaches that are not in the focus of recent literature but hold, in our opinion, great promises. This Account is written from a nanoparticle synthesis chemist's point of view, with focus on synthesis routes and their consequences on the achieved materials. To do so, we concentrate on recent advances by our group and others in this burgeoning field.

\section{Trends in the compositional range of nanoparticles}

Over the last 12 years (Figure 1), the proportion of works on nanoparticles with complex compositions has kept decreasing. This originates first from the nanoscience community moving from the principles of nanoparticles design to their use, thus focusing on conveniently produced systems with recognized properties. A second point is the difficulty to synthesize such complex nanoparticles, which makes the effort less rewarding on a short timescale. One should however note the struggle of several communities to extend the range of compositions at the nanoscale, $, 5,10,11$ as uncovered recently for semiconductor nanocrystals. ${ }^{2}$ These efforts have produced novel properties and motivate further search towards complex solids.

\section{Challenges of nanoparticle design for complex solids}

Complex solids may be multinary compounds and/or rely on complex bonding schemes. Each category is illustrated (Figure 2) by the selenide $\mathrm{Cu}_{2} \mathrm{CdSnSe}_{4}{ }^{2}$ and the boride $\mathrm{SmB}_{62}{ }^{12}$ respectively. The former contains an ordered arrangement of many ions with iono-covalent 
bonding, while the latter features a complex network of covalent B-B bonds into a large unit cell. Crystallizing such structures is a challenge usually overcome by high temperatures to activate atom diffusion in solid-state reactions. These are accompanied by large grain growth and loss of nanostructured materials. For chalcogenides, ${ }^{2}$ reaction conditions can be adjusted in organic solvents below $\sim 300{ }^{\circ} \mathrm{C}$ to yield crystalline nanoparticles (nanocrystals). This illustrates the first approach to overcome the complexity threshold in nanoparticles: tuning reaction pathways through reactive reagents, in order to decrease the reaction temperature. Other examples of such solution (colloidal) syntheses below $300{ }^{\circ} \mathrm{C}$ are found for some phosphides, ${ }^{5,13}$ alloys, ${ }^{10}$ carbides, ${ }^{14}$ lead halide perovskites (LHP) ${ }^{15}$ and oxide nanoparticles, ${ }^{16}$ among others. On the other side, solids like most boron-rich borides still require higher $T$ to crystallize, thus calling for alternative protocols.

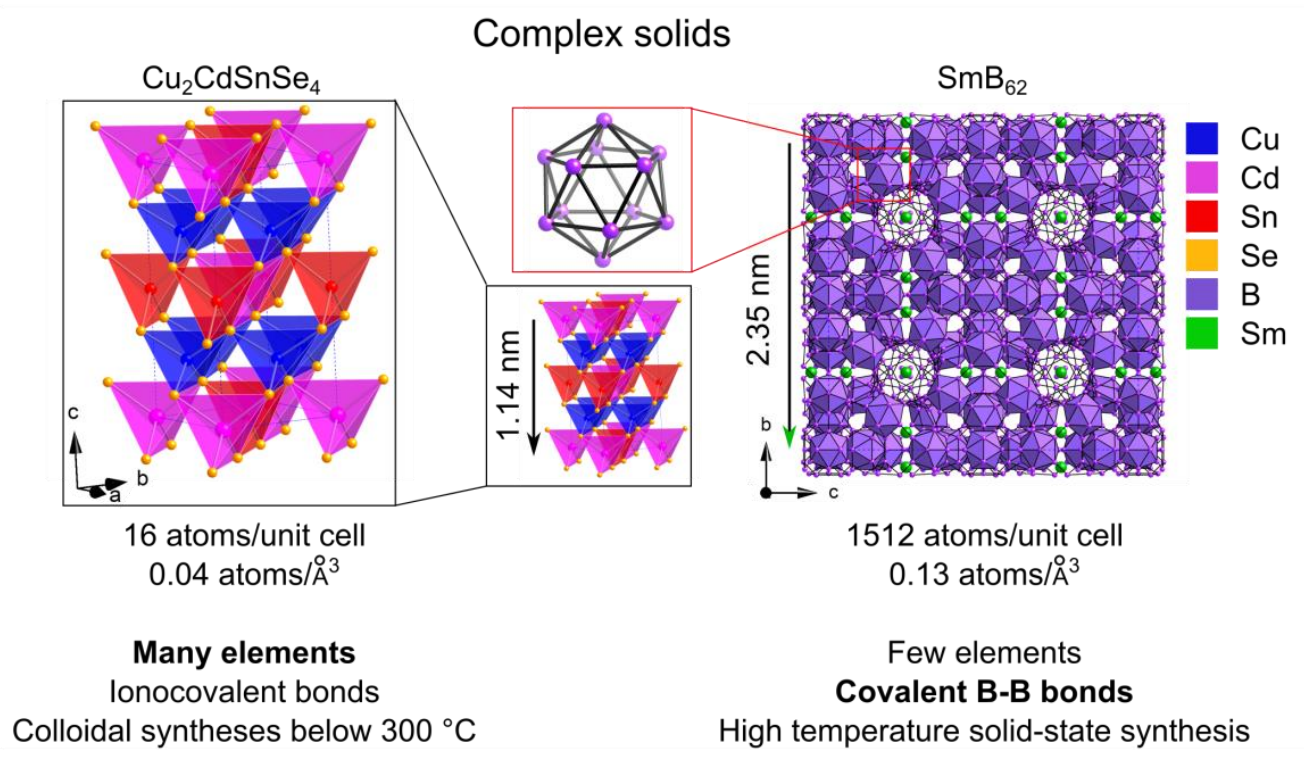

Figure 2. Examples of complex solids encompassing structures made of many elements $\left(\mathrm{Cu}_{2} \mathrm{CdSnSe} 4\right),{ }^{2}$ solids with large unit cells $\left(\mathrm{SmB}_{62}\right)^{12}$ and covalent structures $\left(\mathrm{SmB}_{62}\right){ }^{12}$ 


\section{Overview of synthetic approaches towards nanoparticles}

The toolbox for nanoparticles synthesis is regularly reviewed. ${ }^{2,13,17,18} \mathrm{We}$ discuss relative advantages of main approaches for designing nanoparticles of complex solids (Figure 3 and Table 1).

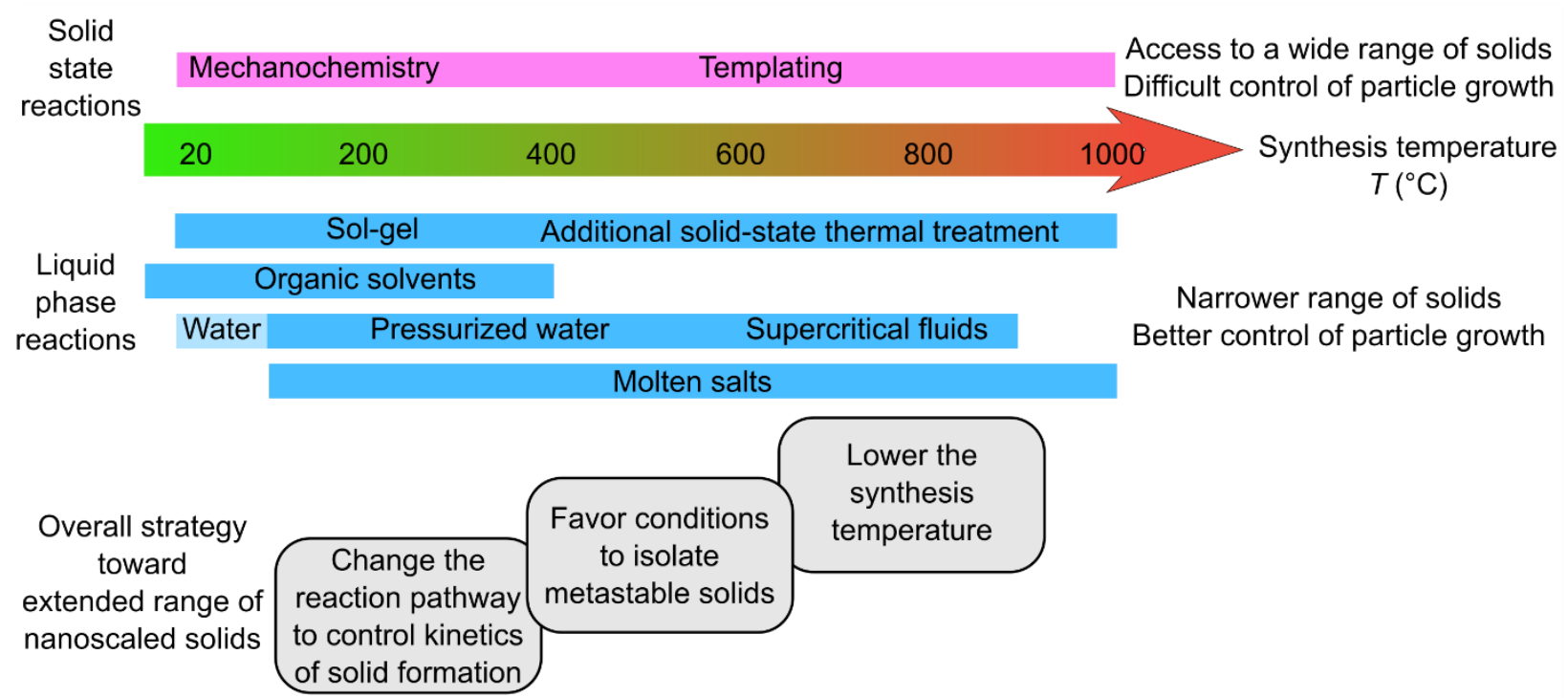

Figure 3. Main protocols and overall strategy for synthesis of complex solid nanoparticles.

Details are given in Table 1. 
Table 1. Main protocols for nanoparticles synthesis: methods to control nanostructures, advantages and limitations.

\begin{tabular}{|c|c|c|c|c|}
\hline & $\begin{array}{l}\text { Approaches/parameters to } \\
\text { control nanostructures }\end{array}$ & Advantages & Limitations & Ref. \\
\hline $\begin{array}{l}\text { Solid state } \\
\text { reactions }\end{array}$ & $\begin{array}{l}\text { - Hard templating } \\
\text { - Gas bubbles templating } \\
\text { - High reactivity } \\
\text { nanoparticles reagents } \\
\text { - mechanosynthesis }\end{array}$ & $\begin{array}{l}\text { Variety of } \\
\text { solids }\end{array}$ & $\begin{array}{l}\text { - Multiple steps } \\
\text { - Only specific reactions } \\
\text { - Restricted to } T \leq 500{ }^{\circ} \mathrm{C} \\
\text { - Limited nanostructure } \\
\text { control }\end{array}$ & $\begin{array}{l}19 \\
20 \\
21 \\
18,22\end{array}$ \\
\hline $\begin{array}{l}\text { Colloidal/sol-gel } \\
\text { syntheses: organic } \\
\text { solvents }\end{array}$ & & & $\begin{array}{l}\text { Restricted by solvent stability } \\
\left(T \leq 400^{\circ} \mathrm{C}\right) \text {, hence narrow } \\
\text { range of solids }\end{array}$ & 2,17 \\
\hline $\begin{array}{l}\text { Colloidal/sol-gel } \\
\text { syntheses: } \\
\text { aqueous media } \\
\text { above } 100{ }^{\circ} \mathrm{C} \text { and } \\
\text { supercritical } \\
\text { fluids }\end{array}$ & $\begin{array}{l}\text { Solvent, reagents, } \\
\text { concentration, } T \text {, surface } \\
\text { ligands. }\end{array}$ & Size control & High pressure set-ups & $\begin{array}{l}13,23- \\
25\end{array}$ \\
\hline $\begin{array}{l}\text { Colloidal/sol-gel } \\
\text { syntheses: } \\
\text { aqueous media } \\
\text { below } 100{ }^{\circ} \mathrm{C} \\
\end{array}$ & $\begin{array}{l}\mathrm{pH}, \text { reagents, } \\
\text { concentration, } T \text {, surface } \\
\text { ligands. }\end{array}$ & $\begin{array}{l}\text { Size, } \\
\text { dispersion } \\
\text { control }\end{array}$ & Narrow range of solids & 26 \\
\hline $\begin{array}{l}\text { Sol-gel process } \\
\text { with post-heat } \\
\text { treatment }\end{array}$ & Reagents, $T$ profile & $\begin{array}{l}\text { - Variety } \\
\text { of } \\
\text { solids } \\
\text { - Shaping }\end{array}$ & Limited nanostructure control & $\begin{array}{l}13,25 \\
27\end{array}$ \\
\hline Molten salts & Extensive nucleation & $\begin{array}{l}\text { Variety of } \\
\text { solids }\end{array}$ & $\begin{array}{l}\text { - Difficult nanostructure } \\
\text { control } \\
\text { - Difficult purification }\end{array}$ & $28-32$ \\
\hline
\end{tabular}

Particle size and dispersion control is low with solid-state and solid-gas ${ }^{13}$ processes, even if few strategies exist to limit grain growth (Table 1). Liquid-phase reactions offer more homogeneous initial distribution of the elements, an advantage to reach multi-element solids. The sol-gel process coupled with thermal post-treatment $\left(T \geq 400{ }^{\circ} \mathrm{C}\right)^{13,25,27}$ can then trigger crystallization of various nanoparticles, but with poor morphology control. Colloidal syntheses enable morphological control but are bound to the solvent stability: organic solvents cannot operate above $400{ }^{\circ} \mathrm{C}$; pressurized set-ups extend the $T$ range with water and supercritical fluids. 
Stable inorganic molten salts operate in the wider $100-1000{ }^{\circ} \mathrm{C}$ range under room pressure, typically for flux synthesis of large single crystals, which rely on limited nucleation events and slow but extended growth. To target nanoparticles in molten salts, one must divert their use to trigger extensive nucleation at the detriment of growth. This approach is much less documented and is focused on solids often accessible through other routes ${ }^{33}$ and at the detriment of particle size and dispersion control, as surface stabilizing ligands are not stable at such temperatures.

Good understanding of liquid-mediated pathways offers large versatility to choose experimental controls for crystal structure, composition, size, shape, surface and dispersion states. In the next sections, we focus on these methodologies already used by specific communities to reach nanostructures of simple solids or complex bulk solids (e.g. aqueous and molten salt synthesis). However, they are usually not employed to target nanostructures of complex solids. More important, they are generally not combined together in a mutual effort towards nanostructured complex solids, as even works dedicated to some nanostructured complex solids rely on one or two methods (e.g. quantum dots ${ }^{2}$ from colloidal synthesis in organic solvents). Because the synthesis of nanoparticles of new complex solids is a strong challenge, the most fruitful scientific method to address the topic is to gather multiple synthetic skills and techniques. This is the approach our group is following.

\section{Soft chemistry for fine tuning of reaction pathways}

Water is the best solvent for cost and environmental concerns, under certain conditions: precursors solubility, possibility of surface charges- or ligands-mediated particle size control and of reaching the targeted phase below $100{ }^{\circ} \mathrm{C}$ (open vials), $250{ }^{\circ} \mathrm{C}$ (conventional autoclaves) or $650{ }^{\circ} \mathrm{C}$ (specially designed autoclaves). The particles should be stable in water, hence precluding 
highly reducing/oxidizing solids. Aqueous syntheses are recognized since decades for their potential in adjusting reaction pathways to drive reactions towards complex solids at the bulk state. ${ }^{34}$ However, precise reaction tuning to yield nanoparticles of such complex solids and to make a selection among several uncommon solids at the nanoscale is mostly unexploited, despite the accessibility of a specific trigger: $\mathrm{pH}$.

We have reported recently the first occurrences of nanostructures for Duttonite $\mathrm{VO}(\mathrm{OH})_{2}$ and Gain's hydrate $\mathrm{V}_{2} \mathrm{O}_{4}\left(\mathrm{H}_{2} \mathrm{O}\right)_{2}$ (Figure 4) by increasing the solubility of vanadium species in water from $\mathrm{pH} 4.0$ to $3.6 .^{35}$ The initial amorphous precipitate evolves in two ways: in situ crystallization of Duttonite at $\mathrm{pH} 4.0$, dissolution-recrystallization of Gain's hydrate at $\mathrm{pH}$ 3.6. We could then obtain first insights into the structure of Gain's hydrate, which undergoes topotactic dehydration upon aging towards Häggite $\mathrm{V}_{2} \mathrm{O}_{3}(\mathrm{OH})_{2}$ nanowires. This highlights the strong sensitivity of reaction pathways in water to $\mathrm{pH}$ values. This parameter enables tuning the cations coordination sphere, then reagents solubility and kinetics of solid formation. 


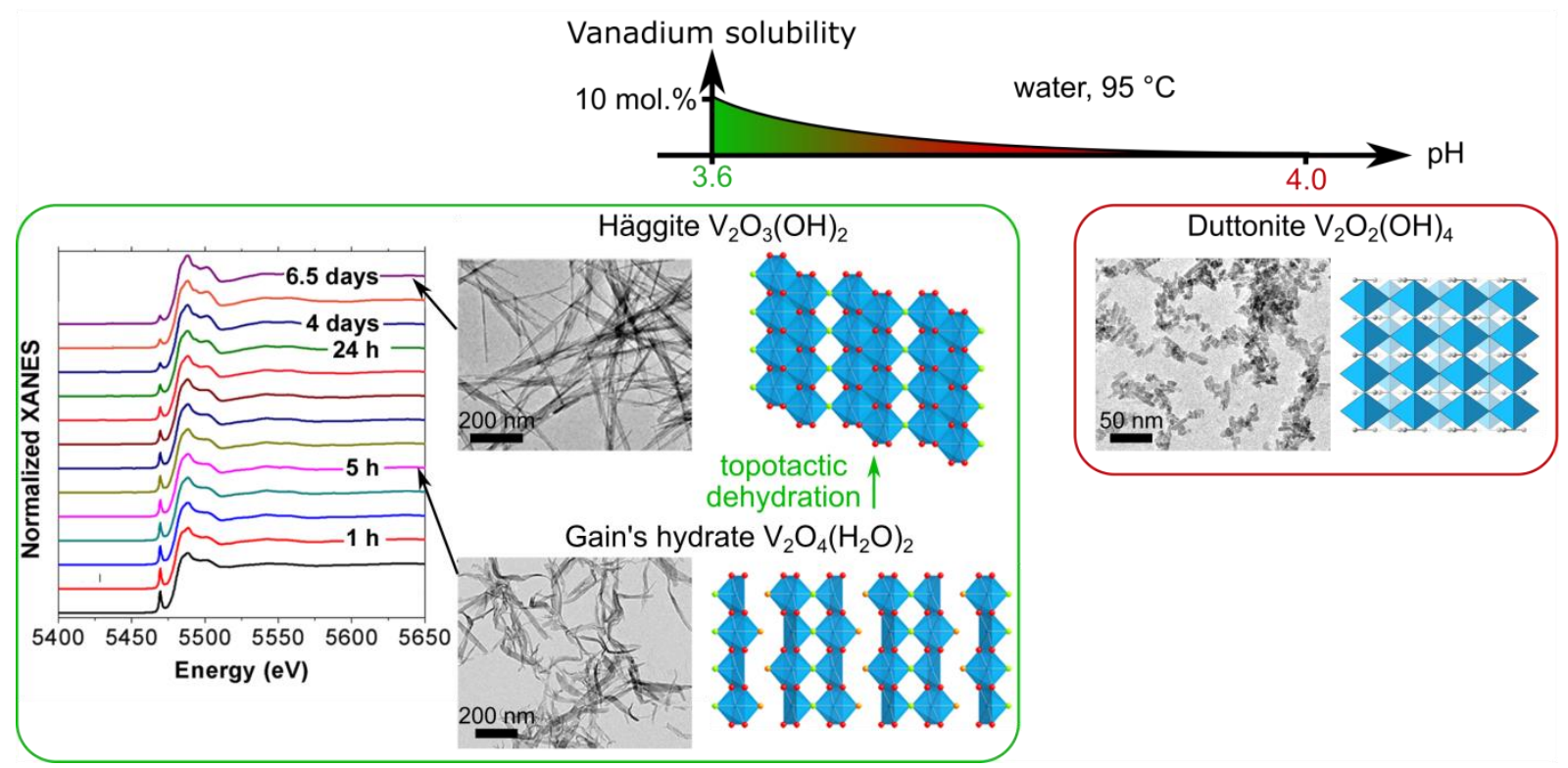

Figure 4. pH-based tuning of reaction pathways in water. Adapted from ref 35. Copyright 2016 American Chemical Society.

Colloidal syntheses can be coupled to microwave heating for high heating efficiency, homogeneity and rate, which fasten the first stage of nanoparticles formation, nucleation, thus leading to smaller particles and narrower size distribution compared to regular heating. Less known is the ability of microwaves to decrease the crystal defect density. This effect was used to design hydrogen peroxide sensors for explosives detection, based on the quenched luminescence of $\mathrm{EuVO}_{4}$ nanoparticles upon $\mathrm{H}_{2} \mathrm{O}_{2}$ exposure. ${ }^{36}$ Microwave-assisted aqueous synthesis led to much fewer surface defects, resulting in doubled luminescence quantum yield, enhanced photostability and increased sensitivity $(<0.1 \mathrm{ppm}$ in vapors $)$ compared to standard heating.

The ability to precisely select reaction pathways and yield high crystallinity objects parallels protocols in organic solvents, ${ }^{2}$ but aqueous syntheses are special in that they yield ligand-free surfaces ready for catalysis ${ }^{37}$ and sensing. ${ }^{36}$ 


\section{Sol-gel derived processes}

The sol-gel process can yield many nanoscaled solids when it is combined to post-heat treatment of the intermediate products in order to trigger crystallization of complex solids. ${ }^{27,38}$ However, particle morphology is less controlled than with colloidal syntheses that occur only in liquidphase, without further solid-state heat treatment. Still, the main interest of this combined sol-gelsolid state reaction pathway lies in the ability to shape nanoparticle-based materials in various forms. ${ }^{27,38}$

Magnéli phases $\mathrm{Ti}_{n} \mathrm{O}_{2 n-1}(n \geq 4)$ are titanium suboxides offering opportunities in energy storage, ${ }^{39}$ conversion, ${ }^{40,41}$ information technologies ${ }^{42}$ and catalysis. ${ }^{43}$ Indeed, mixed valence $\mathrm{Ti}{ }^{\mathrm{III}} / \mathrm{Ti}^{\mathrm{IV}}$ provides electrical conduction higher than $\mathrm{TiO}_{2}$ and tunable by $n$ values, from semiconductors $\left(\mathrm{Ti}_{8} \mathrm{O}_{15}\right)$ to a metal $\left(\mathrm{Ti}_{4} \mathrm{O}_{7}\right)$ with the high chemical stability of oxides. ${ }^{43} \mathrm{Ti}_{n} \mathrm{O}_{2 n-1}$ phases contain crystallographic shear-planes (Figure 5), formed at high $T,{ }^{43}$ that limit phonon propagation, thus providing low thermal conductivity. This uncommon combination of high electrical conductivity with low thermal conductivity raised interest from the thermoelectricity community. We undertook Magnéli nanoparticles synthesis with stoichiometry control and large yield to produce bulk nanostructured materials after sintering. ${ }^{41}$ These monoliths were expected to show enhanced thermoelectric conversion efficiency from phonon scattering at grain boundaries.

We have combined the sol-gel process with carbothermal reduction that uses carbon as reducing agent (Figure 5). ${ }^{41}$ The one-pot approach consists in heating a gel containing molecular titanium-oxo species and a polymer to trigger the formation of $\mathrm{TiO}_{2}$ nanoparticles, then carbonization of the polymer to embed $\mathrm{TiO}_{2}$ nanoparticles in a carbon matrix, and finally 
reduction of $\mathrm{TiO}_{2}$ nanoparticles into $\mathrm{Ti}_{n} \mathrm{O}_{2 n-1}$ by the surrounding carbon, also acting as a template. The resulting 5-20 nm $\mathrm{Ti}_{n} \mathrm{O}_{2 n-1}$ nanoparticles, with $T$-dependent $n$ values, were embedded in a carbon matrix (5-10 wt. \%). Since our work, synthetic efforts for Magnéli nanomaterials have intensified. ${ }^{39}$ Nonetheless, shaping Magnéli phases remains a difficult task ${ }^{40}$ that we have tackled thanks to sol-gel processability (Figure 5). Spark Plasma Sintering applied to the Magnéli-carbon nanocomposite powder yielded bulk nanostructured materials with maintained particle size and increased thermoelectric figure-of-merit. ${ }^{41}$ Besides, adjusting the organic moieties nature and content enabled changing the initial mixtures from gels to viscous solutions, which were electrospun into microfibers showing a remarkable memristive effect. ${ }^{44}$ 


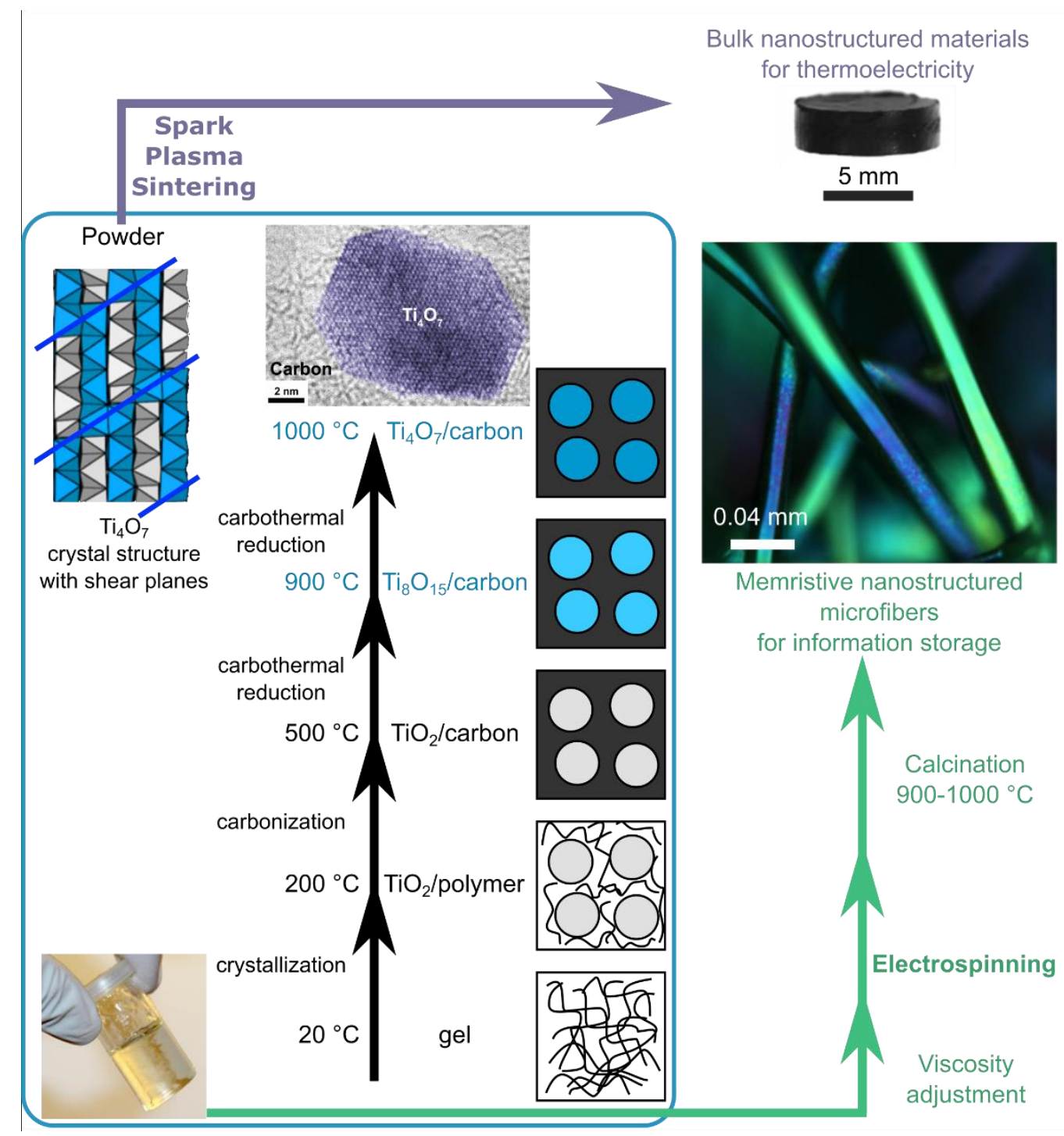

Figure 5. Synthesis and processing of Magnéli $\mathrm{Ti}_{n} \mathrm{O}_{2 n-1}$ nanoparticles. Adapted with permission from refs 41 and 44. Copyright 2011 American Chemical Society and 2014 Wiley-VCH.

\section{Molten salts as liquid media}

Since few years, we are diverting the use of molten salts for flux syntheses of bulk solids. The novelty of the approach is to trigger extensive nucleation with limited grain growth to enable particle size control, through e.g. high precursor concentration, hence high supersaturation, large heating rates and quenching. 


\subsection{Multicationic oxides}

The perovskite structure accommodates a large range of compositions providing extended functionalities ${ }^{45}$ illustrated by LHP for photovoltaics ${ }^{46}$ and optoelectronics. ${ }^{15}$ Oxide perovskites remain highly studied and applied from piezoelectrics, spin/charge transport to catalysis for environment and electrocatalysis for energy. ${ }^{47-49}$ These fields would benefit from well-controlled nanoparticles to understand surface effects and possibly enhance performances. Compared to LHP ${ }^{15}$ and titanate oxides that can crystallize below $200{ }^{\circ} \mathrm{C} .{ }^{17}$ manganese oxide perovskite nanoparticles are challenging to synthesize, as they compete with many intermediate phases ${ }^{50}$ and then crystallize above $600{ }^{\circ} \mathrm{C}$, often with crystal defects.

We have recently reported $\mathrm{La}_{0.67} \mathrm{Sr}_{0.33} \mathrm{MnO}_{3}$ (LSMO) manganite nanoparticles with high crystalline quality (Figure 6) ${ }^{32}$ Such features were achieved at $600{ }^{\circ} \mathrm{C}$ by solution synthesis (Figure 7) to fasten reactions while limiting growth. The thermally stable molten salt $\mathrm{KNO}_{3}$ was sufficiently oxidizing to form high oxidation state species (average $\mathrm{Mn}^{+3.33}$ in LSMO). Metal nitrates and $\mathrm{KNO}_{3}$ were mixed at room temperature and heated. After cooling down, the solidified salt was washed by water. Fast ion diffusion in the liquid yielded highly crystalline nanocubes with narrow size distribution around $20 \mathrm{~nm}$, close to aqueous and colloidal syntheses standards. State-of-the-art transmission electron microscopy (TEM) showed that Mn was indeed $\mathrm{Mn}^{+3.3}$, except for the first two $\mathrm{Mn}$ surface layers. In this $1 \mathrm{~nm}$-thick shell, a high density of oxygen vacancies was counterbalanced by reduction of $\mathrm{Mn}$, while maintaining the perovskite structure. 


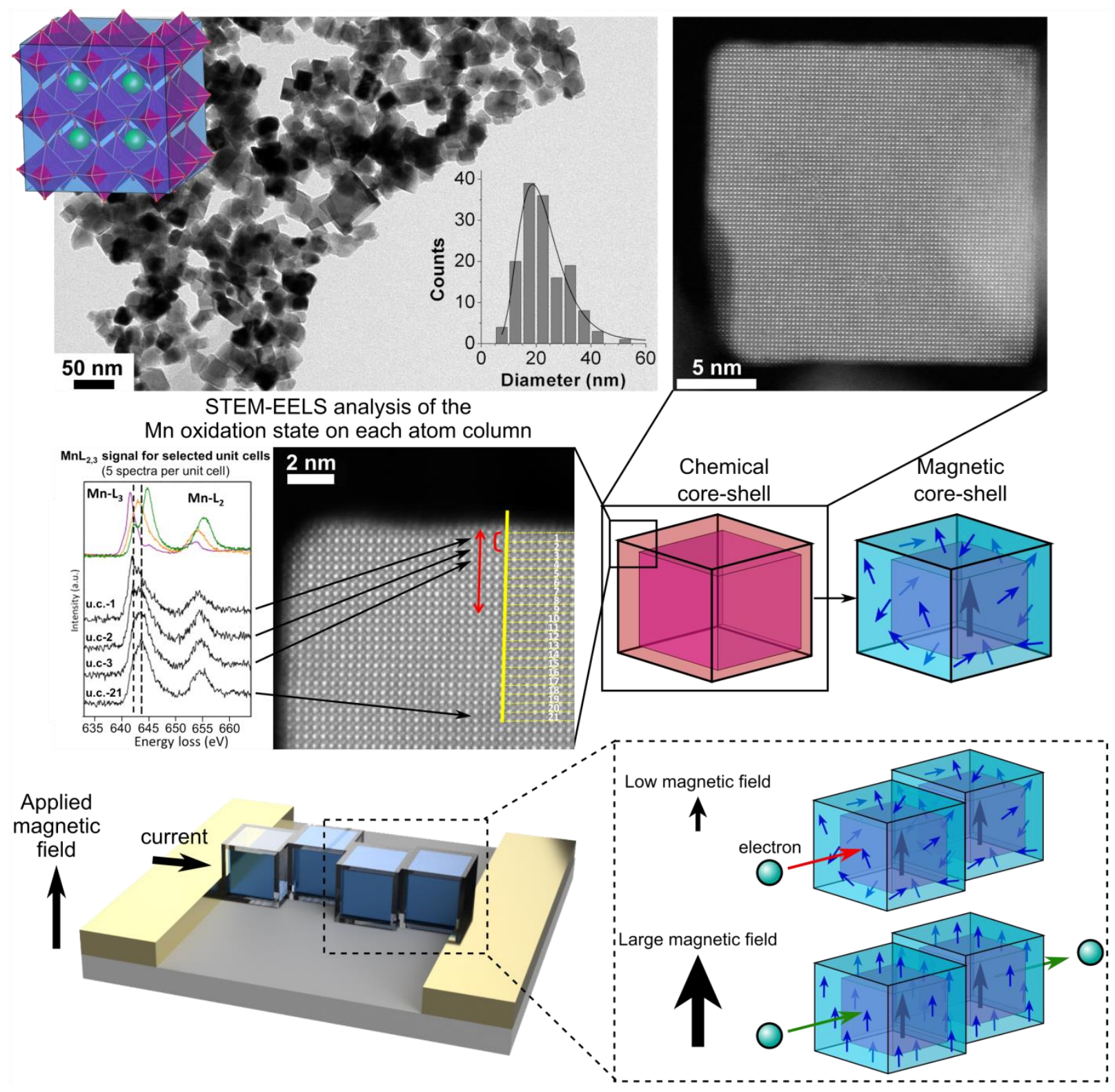

Figure 6. Molten salt derived-LSMO oxide perovskite nanocrystals. Adapted with permission from ref 32. Copyright 2017 Wiley-VCH 


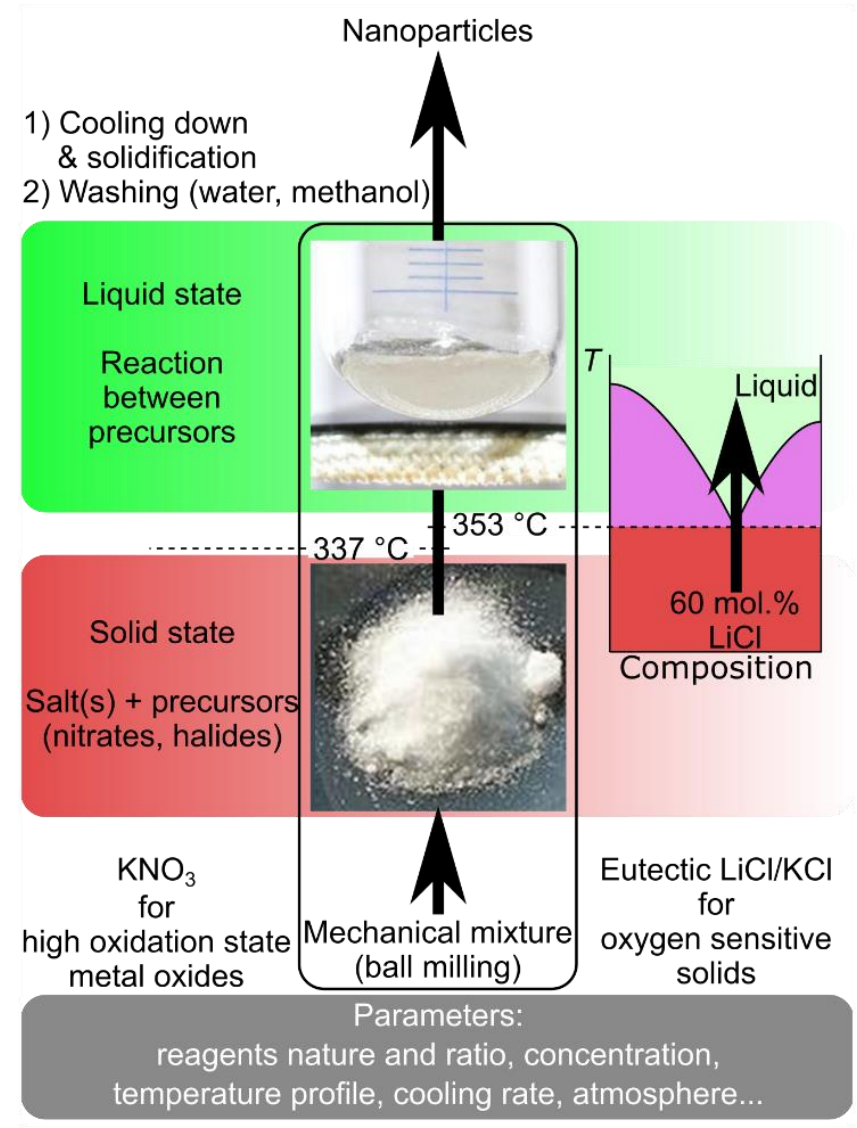

Figure 7. Molten salt-synthesis protocols.

High crystallinity and ligand-free LSMO nanocubes were used as "nano-pieces" of bulk, to exacerbate effects of surface stoichiometry deviations (Figure 6). ${ }^{32}$ A new low $T$ magnetoresistance effect was shown: the shell is a switch for spin transport, where low resistance and spin transfer occur only under large magnetic field when the ferromagnetic core and paramagnetic-like shell magnetizations are aligned. This original magnetotransport sheds new light on the use of LSMO films as spin injectors/detectors, whose transport properties were considered equivalent to the bulk. This effect could be evidenced only by designing ligand-free nanocrystals combining narrow size distribution and crystalline quality mimicking epitaxial thin films. 


\subsection{Non-oxides: boron-based nanoparticles}

Molten salts are not restricted to oxide design: luminescent, ${ }^{29}$ electroactive $^{51}$ B-C-N(-O) nanoparticles are readily synthesized in the eutectic mixture $\mathrm{LiCl} / \mathrm{KCl}$ (Figures 7-8). The approach applies also to nanoparticles of metal borides (Figure 9), whose specificity lies in the strong covalence of boron-boron bonds (section 3) yielding properties without equivalent among common materials: ${ }^{13,52}$ superhardness, superconductivity, catalysis and recently HER electrocatalysis. ${ }^{53,54}$ These properties were evidenced mostly on bulk borides or amorphous nanoparticles difficult to characterize. Crystalline nanoparticles could be more stable and model systems, but their synthesis is challenging (section 3$).{ }^{13}$ To decrease the synthesis temperature and limit grain growth, non-oxidizing molten $\mathrm{LiCl} / \mathrm{KCl}$ was combined with $\mathrm{NaBH}_{4}$ and metal halide reagents. We thus reported at $600-900{ }^{\circ} \mathrm{C}$ first occurrences of many nanoscaled metal borides. ${ }^{13,28,30,31}$ The particles are stable under air, showing a $\sim 2$ nm-thick amorphous shell containing partially oxidized boron. The particle size is controlled by the reagent ratio as in regular liquid-phase synthesis (Figure 9). 

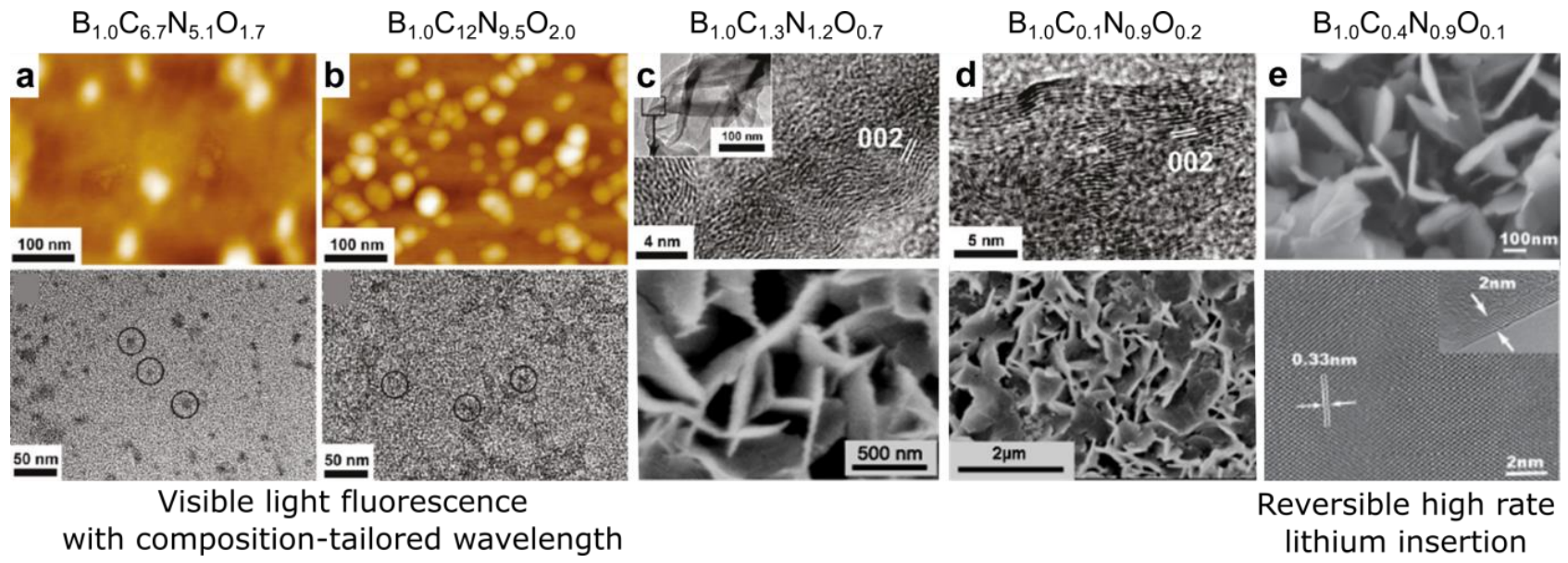

Figure 8. Molten salt-derived nanoscaled B-C-N-O compounds. Adapted with permission from refs 29, 51. Copyrights 2011 American Chemical Society and 2013 Royal Chemical Society.

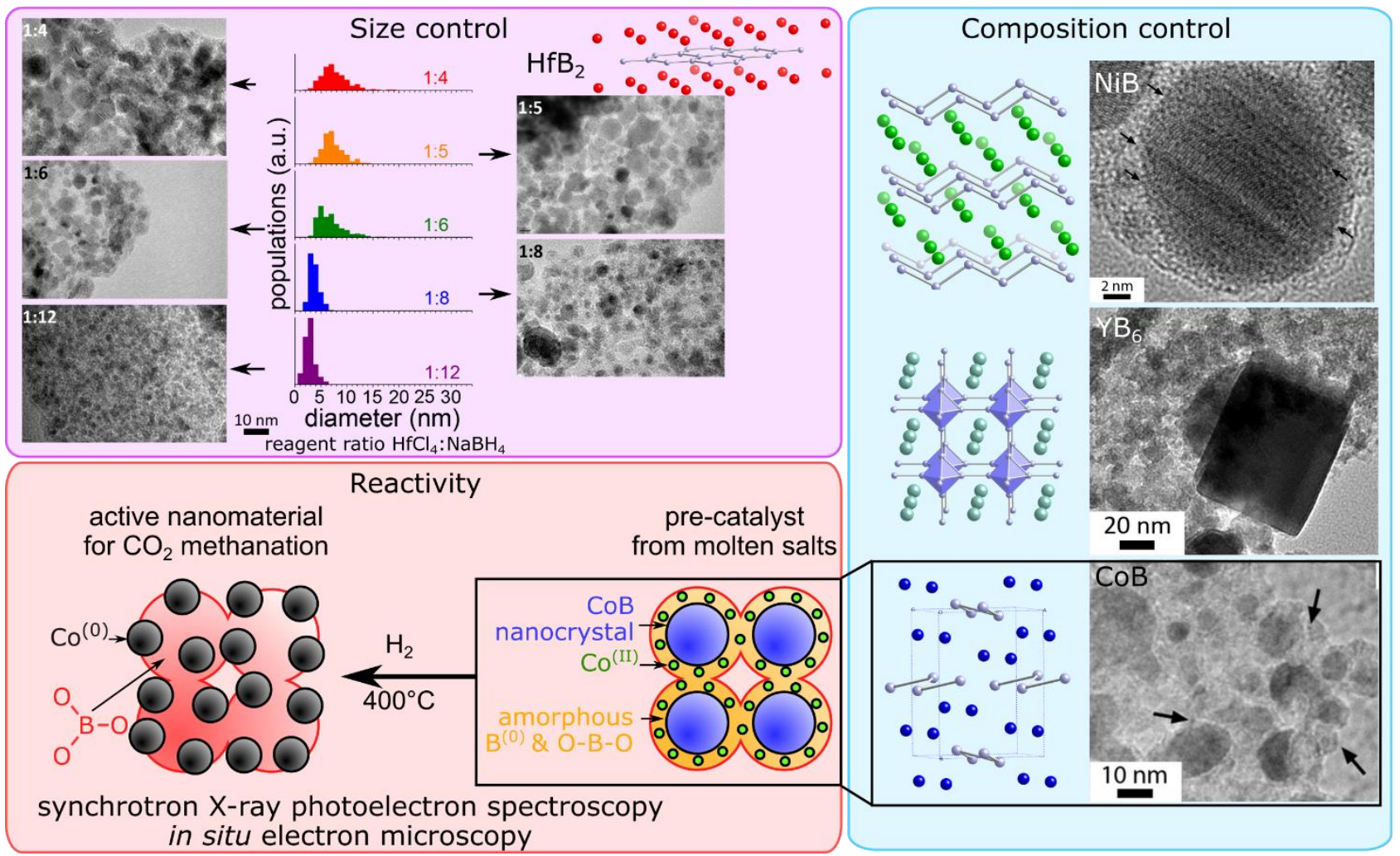

Figure 9. Metal boride nanoparticles: molten-salt synthesis and properties. Size control data are not reported elsewhere. Adapted with permission from refs 13, 28, 30, 31. Copyrights 2013 and 2017 American Chemical Society, 2011 Wiley-VCH and 2016 Royal Chemical Society. 
The activity and selectivity of boride-based (electro)catalysts ${ }^{13,53,54}$ motivate studies of their reactivity under operation conditions. We have undergone combined in situ investigations of compositional, structural and morphological evolutions of molten salt-derived $\mathrm{CoB}$ under different gases up to $600{ }^{\circ} \mathrm{C} .{ }^{31}$ Synchrotron-based Near-Ambient-Pressure X-ray Photoelectron Spectroscopy (NAP-XPS) and TEM with a gas cell highlighted decomposition of CoB nanoparticles, previously exposed to air, into Co nanoparticles and oxidized boron during a pretreatment typical for $\mathrm{CO}_{2}$ methanation $\left(\mathrm{H}_{2}\right.$ at $\left.400{ }^{\circ} \mathrm{C}\right)$. On the contrary, argon atmosphere has no impact. Hence, strong structural changes occur under reactive gases and question the nature of active species in boride-based catalysis. These results find echoes with recently shown metal borides decomposition during the Oxygen Evolution Reaction in aqueous electrolytes. ${ }^{54}$

\section{Understanding and tuning surface states}

Surface states play a primary role in properties discussed above (sensing, ${ }^{36}$ thermoelectricity, ${ }^{41}$ charge $\mathrm{e}^{44}$ and spin $^{32}$ transports, catalysis, ${ }^{37}$ but also ionic conduction $)^{22}$ so that their understanding is of prime importance, by using e.g. photoluminescence, ${ }^{36}$ Raman spectroscopy, ${ }^{37} \mathrm{XPS}^{36}$ and zeta potential measurements. ${ }^{22}$ TEM plays also an increasing role, for state-of-the-art microscopes deliver atom-scale mapping of elements and their chemical state at surface layers. ${ }^{32}$

As a prospect, the example of much simpler gold nanoparticles is instructive, as it shows how hybrid organic-inorganic interfaces can tune surface states and yield novel properties. For instance, grafting aromatic thiols to trigger electron transfer at the interface (Figure 10 $)^{55}$ yields a giant shift of the plasmon band due to a change in the gold core dielectric function. Grafting then 
provides an additional degree of freedom to create new nanomaterials, but before its implementation with complex nanoparticles, their surface reactivity will have to be addressed. In situ characterizations, like NAP-XPS and $\mathrm{TEM}^{31}$ will be pertinent in this context, but again the example of gold particles draws future guidelines to understand hybrid interfaces, especially the organic layer composition and the ligands distribution, by Nuclear Magnetic Resonance ${ }^{56}$ and electron tomography ${ }^{57}$ coupled to Density Functional Theory calculations and molecular dynamic simulations. ${ }^{56,57}$

\section{Hybrid gold nanoparticles for plasmonics}

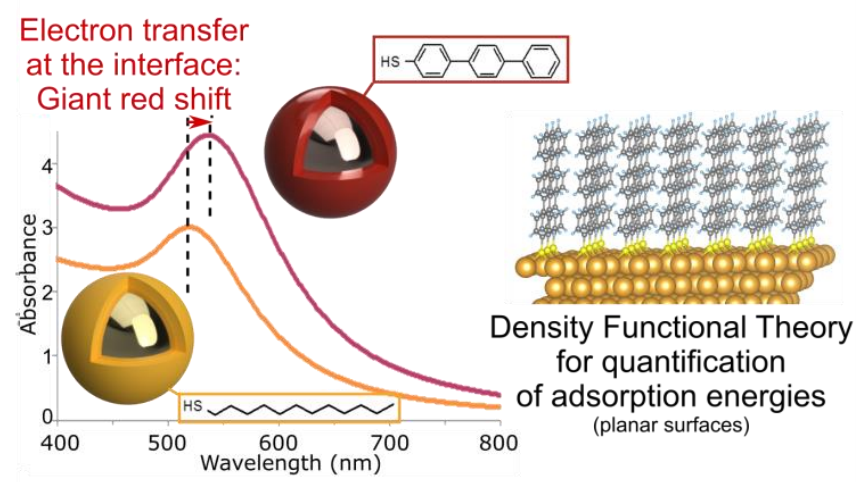

Characterization of molecular distributions Nanoscale heterogeneities in organic shells

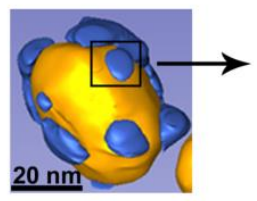

Transmission electron tomography (silica as contrasting agent)

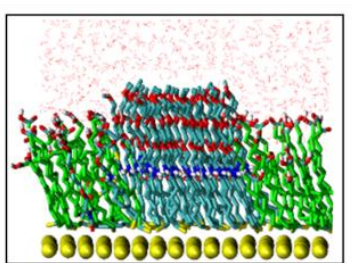

Molecular dynamics (planar surfaces)

Figure 10. Hybrid inorganic-organic core-shell gold-aromatic thiol nanoparticles. Adapted with permission from refs 55-57. Copyrights 2015 and 2017 American Chemical Society, 2017 Wiley-VCH. 


\section{Conclusions, current and future trends}

We have highlighted current efforts for extending the compositional range of inorganic nanoparticles, with emphasis on our recent achievements. We focused on crystalline solids that are metastable and recovered below $100{ }^{\circ} \mathrm{C}$ and those whose crystallization requires temperatures higher than in usual colloidal syntheses discussed elsewhere. ${ }^{2,5}$ Without being exhaustive, the trends we have underlined rely on liquid-phase processes offering the highest degree of control over nanoparticle formation. Most of the procedures relevant to address the topic rely on kinetic control of the reactions to favor nucleation events at the detriment of growth in order to decrease particle sizes. This complicates attempts to computationally predict the outcome of syntheses in terms of particle size and crystal structure, so that experimental rules-of-thumbs are currently the most useful. They encompass:

- Decreasing temperatures versus solid-state reactions to avoid growth by using high reactivity reagents. ${ }^{10,11,13}$ Limitations arise from unavailability of reagents ${ }^{13}$ or the need for high energy input for crystallization. ${ }^{13,32,41}$

- Tuning reaction pathways by adjusting the reactivity of reagents and intermediate phases. This requires understanding formation mechanisms to identify relevant parameters. ${ }^{2,35}$ Knowledge is lacking for molten salts, where in situ characterization and data from water and organic solvents should enlighten crystallization pathways.

- Decreasing synthesis temperatures through liquid-phase pathways, especially with high temperature liquids. ${ }^{27,30-32,41}$ Different stimuli can trigger "nano-crystallization" in liquids, including microwaves ${ }^{36,37}$ or, on the opposite, melt solidification. ${ }^{58}$

Frequently raised issues of the aforementioned methods are scalability, environmental impact, cost and size distribution width. All protocols detailed herein are gram-scale lab syntheses, which 
offer a nice starting point for scale-up, especially with water and molten salts that are green solvents. Environmental impact and cost are also low, even with molten salts thanks to low vapor pressure and recyclability. Size distributions are indeed larger than in mastered colloidal syntheses. ${ }^{2}$ This is the "price to pay" to avoid organic ligands and to readily implement nanoparticles for thermoelectrics, catalysis, sensing and all applications precluded by isolating ligands. $^{2}$ In our procedures, size and shape are controlled through surface charges, reagent ratios, ${ }^{28}$ heat profiles ${ }^{32}$ or epitaxial relationships. ${ }^{59}$ Ligands can be added afterwards at will to target specific properties. Furthermore, if narrow size distributions help understand interface effects and tune properties, ${ }^{2}$ they should not be automatically searched, as best performances are sometimes reached for bimodal or even wider distributions, as for thermoelectricity. ${ }^{58}$ Practical nanocatalysts or sensors also often do not require sub-nanometer size precision. ${ }^{36,37}$ Nonetheless, our achievements show that size control is attainable in molten salts. ${ }^{32}$

The compositional range of nanoparticles should expand in the future, by taking roots in the portfolio of bulk solid-state chemistry to identify potential nanomaterials with new properties. Nanoparticle design is often driven by curiosity and bears a strong exploratory character. Further extension of the compositional range falls in this path: applications may drive towards specific nanomaterials, but the track followed will open trails to other systems. Searching for new nanoparticles is also a playground to discover novel solids, as conditions explored to limit grain growth are those favoring kinetic control of reactions, hence metastable solids, a realm of opportunities for new properties. ${ }^{60}$ The nanoscale also favors low surface energy solids that would be high energy bulk species. ${ }^{61}$ Hence, many novel solids could be retrieved with more complex compositions than those reported. Their discovery is hardly predictable and raises the question of the prediction of new solids, a rapidly evolving field for the bulk ${ }^{7-9}$ but not the 
nanoscale. It will also be up to the scientific community to assess environmental and health impact of these new nanomaterials.

Finally, it is instructive to note that exploratory synthesis has been recognized as essential since the very beginning of organic and inorganic chemistries. The latter still relies strongly on explorations after nearly 150 years, as the outcome of solid-state inorganic syntheses is difficult to predict. ${ }^{6,60}$ Chemistry of nanoparticles is much younger ( 40 years), but the exploration field seems to shrink already (Figure 1). ${ }^{2,60}$ Whether this may be due to modern tools of synthesis and characterization that fasten the fastidious step of synthetic parameter screening, or to applicationoriented research, it is important to maintain the exploration of new nanoscaled solids, as it will continue to be a powerful tool for discovering novel synthetic methods and materials. 


\section{BIOGRAPHICAL INFORMATION}

David Portehault is research scientist of the Centre National de la Recherche Scientifique (CNRS), researcher at LCMCP lab. at Sorbonne Université (SU). He graduated from Ecole Normale Supérieure and received his Ph.D. degree from Université Pierre et Marie Curie (UPMC) in 2008. He has been senior postdoctoral fellow at the Max Planck Institute for Colloids and Interfaces until 2010 when he joined the CNRS. His research covers several topics in nanomaterials chemistry, with a focus on new nanoparticles of complex compositions and synthesis-structure-nanostructure relationships to unveil novel properties and trigger technological advances in nanosciences.

Simon Delacroix graduated from Ecole Normale Supérieure, Cachan, in 2016. He is now Ph.D. graduate student of SU at LCMCP. His work focuses on boron-based nanomaterials for energy conversion.

Guillaume Gouget obtained his Ph.D. from UPMC-SU in 2016 for his work on the synthesis and properties of boron-based nanomaterials at LCMCP. He studies synthetic routes toward various other structures (oxides, sulfides) as a postdoctoral fellow, previously at Institut de Chimie de la Matière Condensée de Bordeaux and currently at the University of Pennsylvania.

Rémi Grosjean graduated from the Ecole Normale Supérieure in 2013 and received his Ph.D. degree from UPMC-SU in 2016 for his work on boron-based nanocomposites. He is now R\&D Engineer in a joint Saint-Gobain/CNRS team addressing indoor air quality issues through roomtemperature catalysis. 
Tsou-Hsi-Camille Chan-Chang obtained her Ph.D. in 2017 from UPMC-SU. Her research at LCMCP focuses on new syntheses of boride nanoparticles, their surface reactivity and properties in catalysis and electrocatalysis.

\section{ACKNOWLEDGEMENTS}

The authors are indebted to collaborators and previous students who contributed to this topic since 2010. Research was supported by CNRS and its Energy Unit, Sorbonne Université, Collège de France, Ministry of Higher Education, Research and Innovation, Region Ile de France through DIM Nano-K and DIM Oxymore, French Defense Agency, French Alternative Energies and Atomic Energy Commission, Solvay-Rhodia, synchrotron SOLEIL, and French state funds managed by the ANR within the Investissements d'Avenir programme ANR-11-IDEX-0004-02, more specifically within the Cluster of Excellence MATISSE. 


\section{REFERENCES}

(1) Inorganic nanoparticles are solids with 3 dimensions below $100 \mathrm{~nm}$ (ISO/TS 800042:2015). They belong to nano-objects, which also encompass nanofibers and nanoplates wolding two and one dimensions below $100 \mathrm{~nm}$, respectively. For sake of simplicity, "nanoparticles" stands for "nano-objects" in this Account.

(2) Kovalenko, M. V.; Manna, L.; Cabot, A.; Hens, Z.; Talapin, D. V.; Kagan, C. R.; Klimov, V. I.; Rogach, A. L.; Reiss, P.; Milliron, D. J.; et al. Prospects of Nanoscience with Nanocrystals. ACS Nano 2015, 9, 1012-1057.

(3) Web of Knowledge, consulted on February 2018, keyword "nanoparticles", restricted to topics "multidisciplinary materials science", "multidisciplinary chemistry" and "nanoscience nanotechnology."

(4) Solozhenko, V. L.; Kurakevych, O. O.; Le Godec, Y. Creation of Nanostuctures by Extreme Conditions: High-Pressure Synthesis of Ultrahard Nanocrystalline Cubic Boron Nitride. Adv. Mater. 2012, 24, 1540-1544.

(5) Callejas, J. F.; Read, C. G.; Roske, C. W.; Lewis, N. S.; Schaak, R. E. Synthesis, Characterization, and Properties of Metal Phosphide Catalysts for the Hydrogen-Evolution Reaction. Chem. Mater. 2016, 28, 6017-6044.

(6) Corbett, J. D. Exploratory Synthesis in the Solid State. Endless Wonders. Inorg. Chem. 2000, 39, 5178-5191.

(7) Jain, A.; Persson, K. A.; Ceder, G. Research Update: The Materials Genome Initiative: Data Sharing and the Impact of Collaborative Ab Initio Databases. APL Mater. 2016, 4, 
053102 1-14.

(8) Oganov, A. R.; Lyakhov, A. O.; Valle, M. How Evolutionary Crystal Structure Prediction Works - and Why. Acc. Chem. Res. 2011, 44, 227-237.

(9) Dyer, M. S.; Collins, C.; Hodgeman, D.; Chater, P. A.; Demont, A.; Romani, S.; Sayers, R.; Thomas, M. F.; Claridge, J. B.; Darling, G. R.; et al. Computationally Assisted Identification of Functional Inorganic Materials. Science 2013, 340, 847-852.

(10) Schöttle, C.; Bockstaller, P.; Popescu, R.; Gerthsen, D.; Feldmann, C. SodiumNaphthalenide-Driven Synthesis of Base-Metal Nanoparticles and Follow-up Reactions. Angew. Chem. Int. Ed. 2015, 54, 9866-9870.

(11) Kanady, J. S.; Leidinger, P.; Haas, A.; Titlbach, S.; Schunk, S.; Schierle-Arndt, K.; Crumlin, E. J.; Wu, C. H.; Alivisatos, A. P. Synthesis of $\mathrm{Pt}_{3} \mathrm{Y}$ and Other Early-Late Intermetallic Nanoparticles by Way of a Molten Reducing Agent. J. Am. Chem. Soc. 2017, $139,5672-5675$.

(12) Sussardi, A.; Tanaka, T.; Khan, A. U.; Schlapbach, L.; Mori, T. Enhanced Thermoelectric Properties of Samarium Boride. J. Mater. 2015, 1, 196-204.

(13) Carenco, S.; Portehault, D.; Boissière, C.; Mézailles, N.; Sanchez, C. Nanoscaled Metal Borides and Phosphides: Recent Developments and Perspectives. Chem. Rev. 2013, 113, 7981-8065.

(14) Meffre, A.; Mehdaoui, B.; Kelsen, V.; Fazzini, P. F.; Carrey, J.; Lachaize, S.; Respaud, M.; Chaudret, B. A Simple Chemical Route toward Monodisperse Iron Carbide Nanoparticles Displaying Tunable Magnetic and Unprecedented Hyperthermia Properties. Nano Lett. 2012, 12, 4722-4728. 
(15) Huang, H.; Bodnarchuk, M.; Kershaw, S. V; Kovalenko, M. V.; Rogach, A. L. Lead Halide Perovskite Nanocrystals in the Research Spotlight: Stability and Defect-Tolerance. ACS Energy Lett. 2017, 2, 2071-2083.

Oh, M. H.; Yu, T.; Yu, S.-H.; Lim, B.; Ko, K.-T.; Willinger, M.-G.; Seo, D.-H.; Kim, B. H.; Cho, M. G.; Park, J.-H.; et al. Galvanic Replacement Reactions in Metal Oxide Nanocrystals. Science 2013, 340, 964-968.

(17) Deshmukh, R.; Niederberger, M. Mechanistic Aspects in the Formation, Growth and Surface Functionalization of Metal Oxide Nanoparticles in Organic Solvents. Chem. Eur. J. 2017, 23, 8542-8570.

(18) Do, J.-L.; Friščić, T. Mechanochemistry: A Force of Synthesis. ACS Cent. Sci. 2016, 3, 13 19.

(19) Liu, Y.; Goebl, J.; Yin, Y. Templated Synthesis of Nanostructured Materials. Chem. Soc. Rev. 2013, 42, 2610-2653.

(20) Lei, W.; Portehault, D.; Liu, D.; Qin, S.; Chen, Y. Porous Boron Nitride Nanosheets for Effective Water Cleaning. Nat. Commun. 2013, 4, 1777-1783.

(21) Tominaka, S.; Yoshikawa, H.; Matsushita, Y.; Cheetham, A. K. Topotactic Reduction of Oxide Nanomaterials: Unique Structure and Electronic Properties of Reduced $\mathrm{TiO}_{2}$ Nanoparticles. Mater. Horizons 2014, 1, 106-110.

(22) Qin, S.; Liu, D.; Wang, G.; Portehault, D.; Garvey, C. J.; Gogotsi, Y.; Lei, W.; Chen, Y. High and Stable Ionic Conductivity in 2D Nanofluidic Ion Channels Between Boron Nitride Layers. J. Am. Chem. Soc. 2017, 139, 6314-6320.

(23) Cansell, F.; Aymonier, C. Design of Functional Nanostructured Materials Using 
Supercritical Fluids. J. Supercrit. Fluids 2009, 47, 508-516.

(24) Liu, D.; Lei, W.; Portehault, D.; Qin, S.; Chen, Y.; Novoselov, K. S.; Geim, A. K.;

Morozov, S. V.; Jiang, D.; Katsnelson, M. I.; et al. High N-Content Holey Few-Layered

Graphene Electrocatalysts: Scalable Solvent-Less Production. J. Mater. Chem. A 2015, 3, 1682-1687.

(25) Wang, J.; Hao, J.; Liu, D.; Qin, S.; Portehault, D.; Li, Y.; Chen, Y.; Lei, W. Porous Boron Carbon Nitride Nanosheets as Efficient Metal-Free Catalysts for the Oxygen Reduction Reaction in Both Alkaline and Acidic Solutions. ACS Energy Lett. 2017, 306-312.

(26) Portehault, D.; Cassaignon, S.; Baudrin, E.; Jolivet, J.-P. Twinning Driven Growth of Manganese Oxide Hollow Cones through Self-Assembly of Nanorods in Water. Cryst. Growth Des. 2009, 9, 2562-2565.

(27) García-Márquez, A.; Portehault, D.; Giordano, C. Chromium Nitride and Carbide Nanofibers: From Composites to Mesostructures. J. Mater. Chem. 2011, 21, 2136-2143.

(28) Portehault, D.; Devi, S.; Beaunier, P.; Gervais, C.; Giordano, C.; Sanchez, C.; Antonietti, M. A General Solution Route toward Metal Boride Nanocrystals. Angew. Chem. Int. Ed. 2011, 50, 3262-3265.

(29) Lei, W.; Portehault, D.; Dimova, R.; Antonietti, M. Boron Carbon Nitride Nanostructures from Salt Melts: Tunable Water-Soluble Phosphors. J. Am. Chem. Soc. 2011, 133, 71217127.

(30) Gouget, G.; Beaunier, P.; Portehault, D.; Sanchez, C. New Route toward Nanosized Crystalline Metal Borides with Tunable Stoichiometry and Variable Morphologies. Faraday Discuss. 2016, 191, 511-525. 
(31) Gouget, G.; Debecker, D. P.; Kim, A.; Olivieri, G.; Gallet, J.-J.; Bournel, F.; Thomas, C.; Ersen, O.; Moldovan, S.; Sanchez, C.; et al. In Situ Solid-Gas Reactivity of Nanoscaled Metal Borides from Molten Salt Synthesis. Inorg. Chem. 2017, 56, 9225-9234.

(32) Thi N'Goc, H. Le; Mouafo, L. D. N.; Etrillard, C.; Torres-Pardo, A.; Dayen, J.-F.; Rano, S.; Rousse, G.; Laberty-Robert, C.; Calbet, J. G.; Drillon, M.; et al. Surface-Driven Magnetotransport in Perovskite Nanocrystals. Adv. Mater. 2017, 29, 1604745.

Liu, X.; Fechler, N.; Antonietti, M. Salt Melt Synthesis of Ceramics, Semiconductors and Carbon Nanostructures. Chem. Soc. Rev. 2013, 42, 8237-8265.

(34) Sheets, W. C.; Mugnier, E.; Barnabé, A.; Marks, T. J.; Poeppelmeier, K. R. Hydrothermal Synthesis of Delafossite-Type Oxides. Chem. Mater. 2006, 18, 7-20.

Besnardiere, J.; Petrissans, X.; Ribot, F.; Briois, V.; Surcin, C.; Morcrette, M.; Buissette, V.; Le Mercier, T.; Cassaignon, S.; Portehault, D. Nanoparticles of Low-Valence Vanadium Oxyhydroxides: Reaction Mechanisms and Polymorphism Control by LowTemperature Aqueous Chemistry. Inorg. Chem. 2016, 55, 11502-11512.

(36) Duée, N.; Ambard, C.; Pereira, F.; Portehault, D.; Viana, B.; Vallé, K.; Autissier, D.; Sanchez, C. New Synthesis Strategies for Luminescent $\mathrm{YVO}_{4}: \mathrm{Eu}$ and $\mathrm{EuVO}_{4}$ Nanoparticles with $\mathrm{H}_{2} \mathrm{O}_{2}$ Selective Sensing Properties. Chem. Mater. 2015, 27, 5198-5205.

(37) Gonell, F.; Portehault, D.; Julián-López, B.; Vallé, K.; Sanchez, C.; Corma, A. One Step Microwave-Assisted Synthesis of Nanocrystalline $\mathrm{WO}_{\mathrm{x}}-\mathrm{ZrO}_{2}$ Acid Catalysts. Catal. Sci. Technol. 2016, 6, 8257-8267.

(38) The Sol-Gel Handbook; Levy, D.; Zayat, M., Eds.; WILEY-VCH Verlag: Weinheim, Germany, 2015; Vol. 1-3. 
(39) Tao, X.; Wang, J.; Ying, Z.; Cai, Q.; Zheng, G.; Gan, Y.; Huang, H.; Xia, Y.; Liang, C.; Zhang, W.; et al. Strong Sulfur Binding with Conducting Magnéli-Phase Ti. Nano Lett. 2014, 14, 5288-5294.

(40) Ma, M.; You, S.; Liu, G.; Qu, J.; Ren, N. Macroporous Monolithic Magnéli-Phase Titanium Suboxides as Anode Material for Effective Bioelectricity Generation in Microbial Fuel Cells. J. Mater. Chem. A 2016, 4, 18002-18007.

(41) Portehault, D.; Maneeratana, V.; Candolfi, C.; Oeschler, N.; Veremchuk, I.; Grin, Y.; Sanchez, C.; Antonietti, M. Facile General Route toward Tunable Magnéli Nanostructures and Their Use as Thermoelectric Metal Oxide/Carbon Nanocomposites. ACS Nano 2011, 5, 9052-9061.

(42) Kwon, D.-H.; Kim, K. M.; Jang, J. H.; Jeon, J. M.; Lee, M. H.; Kim, G. H.; Li, X.-S.; Park, G.-S.; Lee, B.; Han, S.; et al. Atomic Structure of Conducting Nanofilaments in TiO2 Resistive Switching Memory. Nat. Nanotechnol. 2010, 5, 148-153.

(43) Walsh, F. C.; Wills, R. G. A. The Continuing Development of Magnéli Phase Titanium Sub-Oxides and Ebonex® Electrodes. Electrochim. Acta 2010, 55, 6342-6351.

(44) Maneeratana, V.; Portehault, D.; Chaste, J.; Mailly, D.; Antonietti, M.; Sanchez, C. Original Electrospun Core-Shell Nanostructured Magnéli Titanium Oxide Fibers and Their Electrical Properties. Adv. Mater. 2014, 26, 2654-2658.

(45) Xia, Z.; Poeppelmeier, K. R. Chemistry-Inspired Adaptable Framework Structures. Acc. Chem. Res. 2017, 50, 1222-1230.

(46) NREL Best Research Cell Efficiencies https://www.nrel.gov/pv/assets/images/efficiencychart.png (accessed Aug 1, 2017). 
(47) Shao, J.; Liu, H.; Zhang, K.; Yu, Y.; Yu, W.; Lin, H.; Niu, J.; Du, K.; Kou, Y.; Wei, W.; et al. Emerging Single-Phase State in Small Manganite Nanodisks. Proc. Natl. Acad. Sci. 2016, 113, 9228-9231.

Li, W. B.; Wang, J. X.; Gong, H. Catalytic Combustion of VOCs on Non-Noble Metal Catalysts. Catal. Today 2009, 148, 81-87.

(49) Suntivich, J.; May, K. J.; Gasteiger, H. A.; Goodenough, J. B.; Shao-Horn, Y. A Perovskite Oxide Optimized for Oxygen Evolution Catalysis from Molecular Orbital Principles. Science 2011, 334, 1383.

(50) Portehault, D.; Cassaignon, S.; Baudrin, E.; Jolivet, J.-P. Evolution of Nanostructured Manganese (Oxyhydr)oxides in Water through $\mathrm{MnO}_{4}{ }^{-}$Reduction. Cryst. Growth Des. 2010, 10, 2168-2173.

(51) Lei, W.; Qin, S.; Liu, D.; Portehault, D.; Liu, Z.; Chen, Y. Large Scale Boron Carbon Nitride Nanosheets with Enhanced Lithium Storage Capabilities. Chem. Commun. 2013, $49,352-354$

(52) Akopov, G.; Yeung, M. T.; Kaner, R. B. Rediscovering the Crystal Chemistry of Borides. Adv. Mater. 2017, 1604506.

(53) Park, H.; Encinas, A.; Scheifers, J. P.; Zhang, Y.; Fokwa, B. P. T. Boron-Dependency of Molybdenum Boride Electrocatalysts for the Hydrogen Evolution Reaction. Angew. Chem. Int. Ed. 2017, 92521, 5575-5578.

(54) Masa, J.; Weide, P.; Peeters, D.; Sinev, I.; Xia, W.; Sun, Z.; Somsen, C.; Muhler, M.; Schuhmann, W. Amorphous Cobalt Boride $\left(\mathrm{Co}_{2} \mathrm{~B}\right)$ as a Highly Efficient Nonprecious Catalyst for Electrochemical Water Splitting: Oxygen and Hydrogen Evolution. Adv. 
Energy Mater. 2016, 6, 1502313.

(55) Goldmann, C.; Lazzari, R.; Paquez, X.; Boissière, C.; Ribot, F.; Sanchez, C.; Chanéac, C.; Portehault, D. Charge Transfer at Hybrid Interfaces : Plasmonics of Aromatic ThiolCapped Gold Nanoparticles. ACS Nano 2015, 9, 7572-7582.

(56) Goldmann, C.; Ribot, F.; Peiretti, L. F.; Quaino, P.; Tielens, F.; Sanchez, C.; Chanéac, C.; Portehault, D. Quantified Binding Scale of Competing Ligands at the Surface of Gold Nanoparticles: The Role of Curvature and Intermolecular Forces. Small 2017, 13, 1604028.

(57) Meena, S. K.; Goldmann, C.; Nassoko, D.; Seydou, M.; Marchandier, T.; Moldovan, S.; Ersen, O.; Ribot, F.; Chanéac, C.; Sanchez, C.; et al. Nanophase Segregation of SelfAssembled Monolayers on Gold Nanoparticles. ACS Nano 2017, 11, 7371-7381.

(58) Tan, G.; Zhao, L. D.; Kanatzidis, M. G. Rationally Designing High-Performance Bulk Thermoelectric Materials. Chem. Rev. 2016, 116, 12123-12149.

(59) Portehault, D.; Cassaignon, S.; Baudrin, E.; Jolivet, J.-P. Synthesis of a Manganese Oxide Nanocomposite through Heteroepitaxy in Aqueous Medium. Chem. Commun. 2009, 674676.

(60) Feldmann, C. Metastable Solids-Terra Incognita Awaiting Discovery. Angew. Chem. Int. Ed. 2013, 52, 7610-7611.

(61) Tronc, E.; Chanéac, C.; Jolivet, J. P. Structural and Magnetic Characterization of $\varepsilon-\mathrm{Fe}_{2} \mathrm{O}_{3}$. J. Solid State Chem. 1998, 139, 93-104. 